\title{
INNOVATION AND GOVERNANCE OF THE CANNABIS CROP VALUE CHAIN
}

\author{
Andrea Lugo-Ruiz ${ }^{\mathrm{a}}$, Dr. José María García-Alvarez-Coque ${ }^{\mathrm{b}} \&$ José-David Barberác $^{\mathrm{c}}$
}

${ }^{a}$ Universitat Politècnica de València ( $\underline{\text { andrea.lugo4@upr.edu) }} ;{ }^{b}$ Universitat Politècnica de València (jmgarcia@upvnet.upv.es); ${ }^{c} I N G E N I O$ (CSIC-UPV València) (jobarto@ingenio.upv.es)

\begin{abstract}
In this contribution, we present an overview of the organization and positionings of the cannabis value chain in Europe and the USA. As a first step, attention will be given to the development of the cannabis industry and its main regulatory framework on both sides of the Atlantic. As an emerging and fastdeveloping value chain, consideration will be given to the research and innovation networks identified through bibliometric analysis. The contribution finalizes by reporting on the future steps to assess the main enabling and blocking drivers for the development of the cannabis value chain, understood as an innovative value chain where various actors interact within this highly regulated agricultural sector.
\end{abstract}

KEYWORDS: Cannabis, public policy, bibliometrics, value chain, Scopus-indexed papers

\section{Introduction and objectives}

The legalization of cannabis is currently receiving attention globally, and many countries find themselves decriminalizing and or legalizing cannabis use, therefore establishing policies to regulate this innovating market (Riley, Vellios, \& van Walbeek, 2019). Further cannabis knowledge is imperative to understand its positioning in the agri-food system. Understanding the regulatory framework and the diversity of entry points of the cannabis knowledge and innovation system is a fundamental step to devise their future prospects of development and its potential societal impacts. As a core objective, we aim at mapping the cannabis' entry points for innovation and identifying its networks through a bibliometric analysis. We aim to identify innovations in the cannabis industry and their main drivers. This effort will pave the way to identifying market regulations and their relation to innovations and consumers' perceptions.

Cannabis sativa are plants of the Cannabaceae family. Their attributes vary in a wide range of beneficial impacts. In fact, cannabis has been proven to be around since the development of agriculture. Li \& Lin (1974) found the primary evidence of the use of cannabis was originate in China. Historical research discovered the use of this plant for cultivating fibers since 4,000 BC ( $\mathrm{Li} \& \mathrm{Lin}, 1974)$. The development of cannabis in Western medicine begun in the $19^{\text {th }}$ century, with various applications on different diseases and medicinal prescriptions. Nonetheless, during the beginning of the $20^{\text {th }}$ century, the use of cannabis in Western medicine dramatically decreased given the inconsistencies perceived in the cannabis plant potency range (Zuardi, 2006). Therefore, in the past two centuries, cannabis plants have had eminent political controversies and social stigma worldwide. However, in the last decade, researchers are still studying the plant to determine the specific medical benefits of the cannabinoids it contains. There are over 100 cannabinoids found in the plant, although research mainly focuses on CBD and THC compounds. (Potter, 2013). The door is open to emerging initiatives that deserve consideration from social and economic perspectives.

In most parts of Europe, CBD products can be purchased as herbs, resin, oils, food supplements, and cosmetics (Manthey, 2019). The European Monitoring Centre for Drugs and Drug Addiction (EMCDDA, 1993) found that the frequency of cannabis use in Europe differs mainly by country, noting a higher frequency in the Mediterranean region and Western Europe, being the Netherlands the country with most new cannabis users in Europe. This variation could be attributed to the restrictive regulatory framework and the possibility of a stigma in users' perception (Lashley \& Pollock (2020). Nonetheless, the EMCDDA states that cannabis use has remained largely stable in Europe in recent years.

In comparison, the United States regulates cannabis use through the Department of Agriculture for CBD and the Public Health Department jointly with the Bureau of Cannabis Control for cannabis containing more than $0.03 \%$ THC. The 2014 Farm Bill allowed institutes of higher education and state departments of agriculture to grow industrial hemp to obtain fiber and CBD for research under an agricultural pilot program. Therefore, it was an experimental approval phase (USDA, 2014). Moreover, the 2018 Farm Bill 
allowed Cannabis sativa L. cultivation, processing, and distribution permits for all agricultural initiatives that comply with the application requisites. To that extend, we must recognize that though cannabis is still illegal at a federal level due to its Schedule 1 classification, the National Conference of State Legislatures found that a total of 36 US states, District of Columbia, Guam, Puerto Rico, and US Virgin Islands have approved complete, publicly available medical cannabis programs. In addition, as of April 14, 2021, 17 states, two territories, and the District of Columbia have enacted legislation to regulate cannabis for adult use (NCSL, 2021). Regulatory changes and innovation in the USA are pushing the industry to grow fast. In 2017, the sales for the United States Cannabis sativa L. Industry were $\$ 820 \mathrm{~mm}$ total. From that total, $\$ 190 \mathrm{~mm}$ were derived from CBD products, $\$ 181 \mathrm{~mm}$ were for personal care products, and $\$ 137 \mathrm{~mm}$ were for food products derived from hemp (Hemp Business Journal 2018). The Expert Market Research experts (2020) state that the global industrial hemp market reached \$5 billion in 2020. The market projects a continuous increased growth at a stable increased rate in the forecast period of 2021-2026, with a forecast value of approximately \$24 billion by 2026 (Expert Market Research , 2021).

\section{Methodology}

We consider the analysis of web-based documents as a first step to identify the networks of collaboration in the cannabis industry. This visualization will allow portraying not only to depict networks but also to identify a cluster of stakeholders and their main characteristics. Network analysis assumes that any actor typically participates in a network system involving other significant reference points in decision-making processes (Cantner \& Graf, 2006) (Knoke \& Kuklinski, 1982). As a first approximation, the present contribution considers the public and private stakeholders involved in research and innovation related to cannabis. Bibliometric data was extracted from the Scopus database, the largest abstract and citation database of peer-reviewed literature. This database includes scientific journals, books, and conference proceedings. In May 2021, we queried Scopus with string: TOPIC = (ALL (cannabis) AND ALL ( CBD ) AND ALL ( THC ) ) AND ( LIMIT-TO ( OA,"publisherfullgold" )). Scopus features smart tools to track, analyze and visualize research.

\section{Results}

During 2001-2021, in order of amount of research documents published per category, we have Medicine (271), Biochemistry, Genetics and Molecular Biology (190), Pharmacology, Toxicology and Pharmaceutics (136), Chemistry (81), Agricultural and Biological Sciences (76), Neuroscience (75), Multidisciplinary (61), Chemical Engineering (50), Computer Science (36), Immunology and Microbiology (29), Environmental Science (23), Veterinary (12), Psychology (10), Nursing (7), Social Sciences (7), Materials Science (6), Engineering (5), Physics and Astronomy (5), Earth and Planetary Sciences(3), Energy(3), Health Professions (2). Graph 1 illustrates the number of published cannabis documents based on high-impact research journals. None of them were developed at a consistent growth rate, although most of them seemed to have established a new peak in 2020.

Graph 1: Documents per year by source (2012-2021)

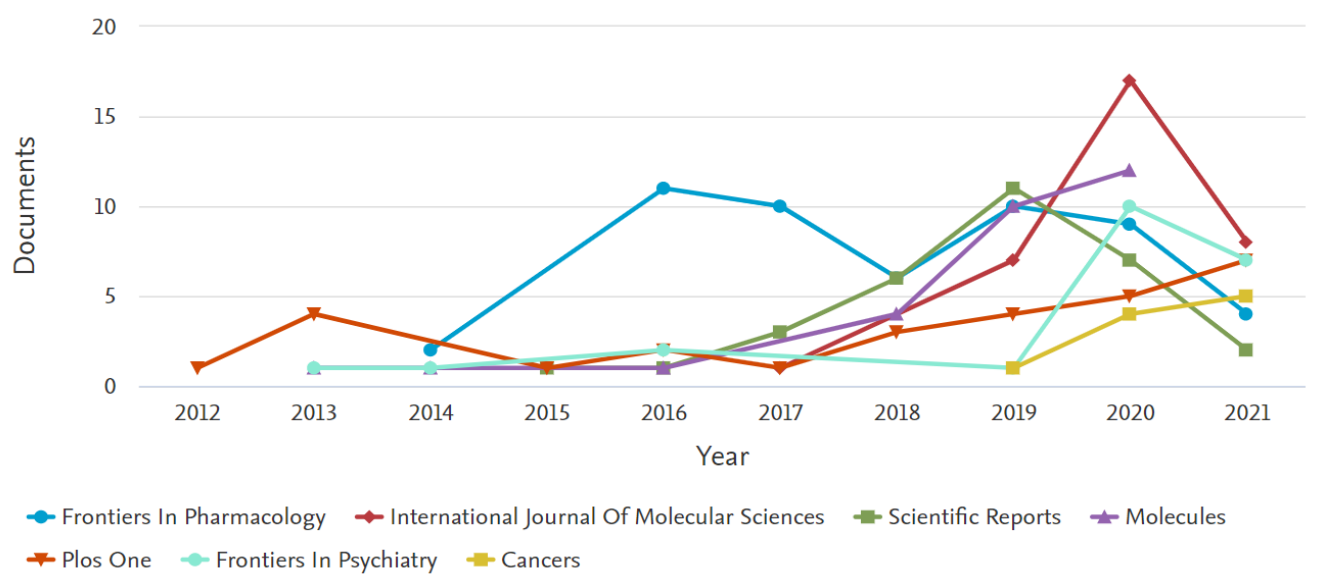

The biggest category with $24.9 \%$ of the pie chart was medicine, holding the most published documents in the category. Followed by Biochemistry, Genetics, and Molecular Biology with 190 published 
documents. Graph 2 shows the number of documents published on cannabis by country, and the scale shows gold access in the Scopus network. We can observe a wide variety of international contributions and interest in the cannabis topic.

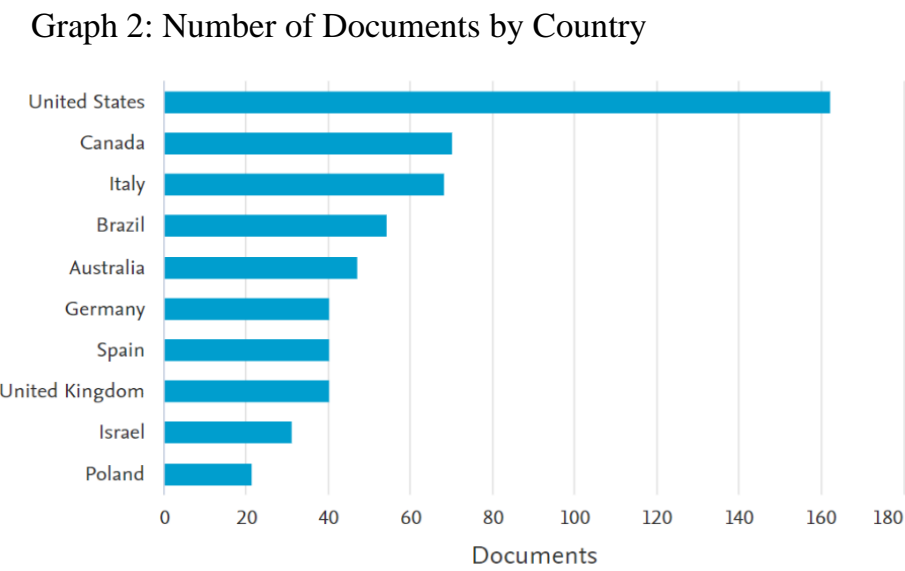

\section{Conclusion and further steps}

A close analysis of Cannabis sativa L., known as hemp, indicates a recent substantial increase in production, effortless accessibility, sustainable properties, and industrial applications (Musio, Müssig, \& Amaducci, 2018).

This research raises more questions than answers. However, it is an exciting time to research such an innovative market product. Cannabis plants have experienced a changing perspective and acceptance rate across centuries. Nonetheless, we see promising developments that emphasize the quality of the natural resource. Given the results, we can observe that worldwide experiments and applications of cannabis have helped us understand its potential and efficient management for the best results.

Moreover, significant legal and public policy changes are currently being developed, and our research will aid as a base for future research given this new line of investigation. Every day, social acceptability is gradually increasing, and negative stigma towards cannabis plants is diminishing. It is evident that we need a consistent increase in cannabis research, and our goal is to help understand this market, both its limits and opportunities.

The next step as a part of our research process will be to complete the mapping of the cannabis value chain as well as paying close attention to cannabis laws and regulations. In addition, we will be analyzing the direct and indirect impacts of policies that affect the cannabis industry, such as safety regulations, product restrictions, taxation, the incentives to innovation, and other factors that increase its cost and price in the market. Several cannabis-related businesses have profited from its revenue growth but, for the most part, have found it challenging to transform that growth into significant profits. This challenge is mainly caused by the regulatory and taxation levels implicated in cannabis markets, thus the importance of studying these variables (Cornell \& Damodaran, 2020). Nonetheless, we will also be exploring the impacts of recreational and medical cannabis on society. This will be developed as qualitative research that will explain the nature of stigma towards the product.

\section{References}

Cantner, U., \& Graf, H. (2006). The network of innovation in Jena: An application of social network analysis. Research Policy, 35, 463-480. 
Cornell, B., \& Damodaran, A. (2020). The Big Market Delusion: Valuation and Investment Implications. Financial Analysts Journal.

European Monitoring Centre for Drugs and Drug Addiction . (1993). Retrieved from https://www.emcdda.europa.eu/emcdda-home-page_en

Expert Market Research . (2021). https://www.expertmarketresearch.com/.

Knoke, D., \& Kuklinski, J. (1982). Network Analysis. Beverley Hills, CA: Sage.

Lashley, K., \& Pollock, T. G. (2020). Waiting to inhale: Reducing stigma in the medical cannabis industry. Administrative science quarterly, 65(2), 434-482.

Legislatires, N. C. (2021). Retrieved from https://www.ncsl.org/research/health/state-medical-marijuanalaws.aspx

Li , H. L., \& Lin, H. (1974). An archaeological and historical account of cannabis in China. Economic Botanics, 28(4), 437-447.

Manthey, J. (2019). Cannabis use in Europe: Current trends and public health concerns 68. International Journal of Drug and Policy, 68, 93-96.

Musio, S., Müssig, J., \& Amaducci, S. (2018). Optimizing Hemp Fiber Production for High Performance Composite Applications. Plant Science.

Potter, D. J. (2013). A review of the cultivation and processing of cannabis (Cannabis sativa L.) for production of prescription medicines in the UK. Drug Testing and Analysis, 6(2), 31-38.

Riley, S., Vellios, N., \& van Walbeek, C. (2019). An economic analysis of the demand for cannabis: some results from South Africa. Drugs: Education, Prevention and Policy, 1464-1470.

Russo, E. (2004). Future of Cannabis and Cannabinoids in Therapeutics. Journal of Cannabis Therapeutics, 163-174.

The US hemp industry grows to $\$ 820$ million in sales in $2017 \mathrm{https}: / / \mathrm{www}$.hempbizjournal.com/size-ofus-hemp-industry-2017/. (2018). Hemp Business Journal. Retrieved from https://www.hempbizjournal.com/size-of-us-hemp-industry-2017/

USDA. (2014). https://www.usda.gov/farmbill.

Zuardi, A. W. (2006). History of cannabis as a medicine: a review. Brazilian Journal of Psychiatrics 